\title{
PERFORMANCE BASED EARTHQUAKE ASSESSMENT OF AN INDUSTRIAL SILOS STRUCTURE AND RETROFIT WITH SLIDING ISOLATORS
}

\author{
Edoardo Rossi ${ }^{1}$, Michelangelo Ventrella ${ }^{1}$, Marco Faggella ${ }^{1}$, Rosario Gigliotti ${ }^{1}$, Franco \\ Braga $^{1}$ \\ ${ }^{1}$ Università degli studi “La Sapienza” di Roma \\ Via Eudossiana 18 \\ e-mail: \{edoardo.rossi, michelangelo.ventrella, marco.faggella, rosario.gigliotti, franco.braga\}@ uni- \\ roma1.it
}

Keywords: Industrial Plants, Performance based assessment, Incremental Dynamic Analyses, Retrofit, Friction Isolators.

\begin{abstract}
Recent seismic events pointed out the high vulnerability of existing industrial facilities, stressing on safety and high losses inherent to interruption of economic activities and release of environmentally hazardous materials. These structures often have irregular geometry and structural configuration, are subject to aging and corrosion, and are designed without specific performance-based or seismic design criteria. Due to these inherent complexities, retrofit using friction isolators can be a viable and practical solution for performance improvements. This work presents a case study of irregular industrial storage plant structure consisting of a group of six elevated silos resting on a steel frame on one side and connected to a vaulted RC structure on the other. A computational model is built incorporating nonlinearities from the components (braces, beams, columns, etc.) and from the mitigation devices. Retrofit using friction isolators is analyzed and evaluated through linear and nonlinear dynamic analyses under a set of natural ground motions. Results show the effectiveness of the mitigation strategy in terms of performance improvement.
\end{abstract}




\section{INTRODUCTION}

Recent seismic events (Bam 2003, Chile 2010, Fukushima 2011, Emilia 2012, etc.) [1-4] pointed out the high vulnerability of industrial plants both in life threatening, economical losses and environmental contamination terms. Damages were observed both in structural and nonstructural components such as mechanical equipment, piping systems and storage racks. The consequences of such damages ranged from the complete collapse of the structure to interruption of the activities, including the triggering of fires and the release of hazardous content.

Within the framework of the Seismic PROtection of INDUSTRial plants by enhanced steel based sYstems (PROINDUSTRY) project, a group of case studies has been selected. Each case study is representative of a particular category of structures, depending on the geometry, the activity of the plant and the type of material processed. This paper presents a retrofit solution of a storage structure consisting of a group of elevated silos containing sodium percarbonate. The main cause of damage observed on elevated steel silos during earthquakes lies in the failure of the support structure, which generally results in the collapse of the structure [6]. The shell structure of the silo can be considered safe since the acceleration needed to cause buckling phenomena of the wall is generally several times higher than the one causing damage to the substructure or the anchorage [6-8].

The retrofit solution proposed for the structure object of this study focuses on the reduction of the action transmitted to the substructure.

\section{CASE STUDY STRUCTURE}

The case study industrial structure consists of a group of six elevated silos supported by a steel structure and connected on one side to a concrete vaulted industrial building. The silos, located approximately $7 \mathrm{~m}$ above ground, have a cylindrical shape with a diameter of $3.1 \mathrm{~m}$, a height of $6.77 \mathrm{~m}$ and a wall thickness of $5 \mathrm{~mm}$. The content is sodium percarbonate, a typical product used in the cleaning industry, characterized by a weight per unit volume of $1200 \mathrm{~kg} / \mathrm{m}^{3}$. A single silo can contain up to $16.3 \mathrm{~m}^{3}$ of material. The silos rest on a steel structure composed of a deck and two slender columns. The two columns are HEA360 profiles with an S235 steel grade. The deck is composed a series of main beams realized through HSU profiles, several secondary beams (IPE profiles) with the function of transferring the weight of the silos to the main beams and two horizontal bracing systems, located at the top and at the bottom of the HSU profiles, mainly composed of L or double L profiles. The connection to the RC structure is made via two spherical hinges. The concrete structure is composed of four hollow pillars with a dimension of $1400 \times 900 \mathrm{~mm}$ and a central hole of $800 \times 300 \mathrm{~mm}$ and a $30 \mathrm{~mm}$ thick vault anchored to the pillars at a height of $6 \mathrm{~m}$ and with a maximum rise of $2.5 \mathrm{~m}$.
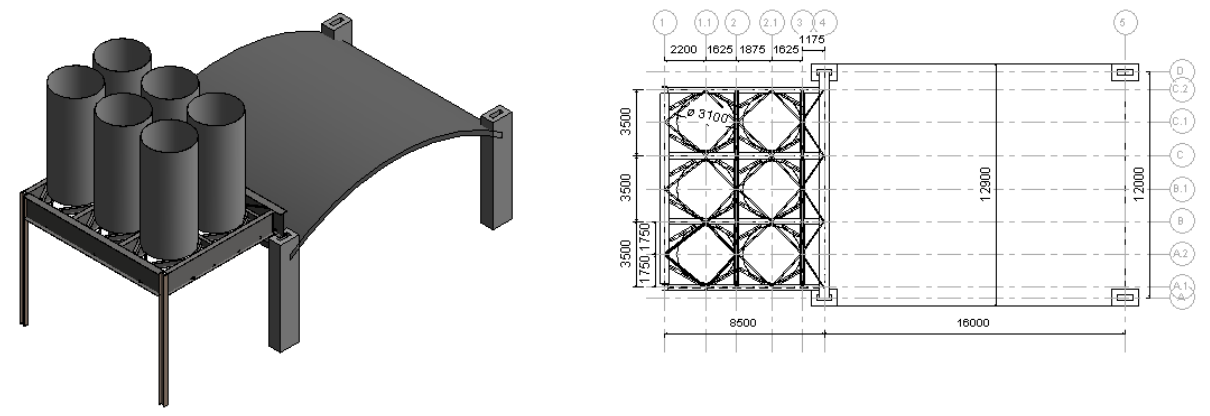

Figure 1: Case study silos structure 3D and plan view.

The actual performance was established through an assessment study of the structure. A preliminary analysis on the components has shown how a traditional or simplified model may lead 
to large errors. In particular the attention was focused on the main beams, the silos and the RC vault. On the first two components the comparison has been carried out between a frame and a shell model. The last one was investigated in terms of actions transmitted to the steel structure and of stiffness. Comparisons are reported in Figure 2. The numerical model was built using SAP2000. The main beams have been modeled through linear elastic shell elements with connection only on the web. The secondary beams have been modeled as frame elements with fiber plastic hinges while the braces have been modeled using multi-linear plastic links incorporating a phenomenological model for their buckling hysteresis cycle. The steel columns are modeled with frame elements and fiber plastic hinges. The concrete structure is linear elastic; the pillars are modeled with frame elements while the vault is made with shell elements. The foundations blocks are modeled with rigid shell elements to simulate the soil-structure interaction with linear springs. The silos are modelled through elastic shell elements with distributed mass so to correctly account for their deformability.
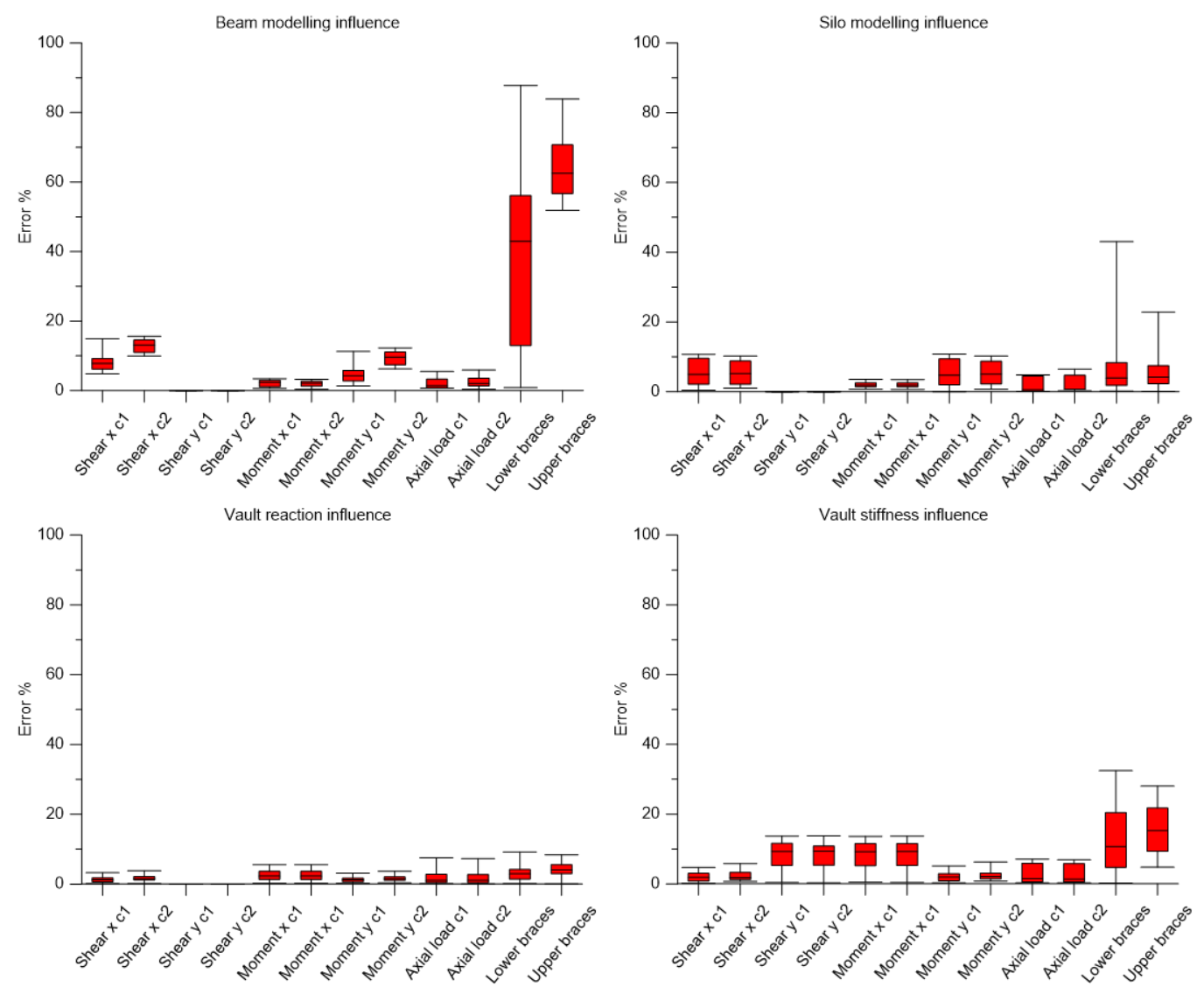

Figure 2: Influence of the different models in the numerical response of the structure.

Static and dynamic analyses, which considered the variability of the action through through a suite of earthquake records [9], were used to establish the main damage causes, which were due to a fragile failure of the steel columns, caused by buckling effects, resulting in a complete collapse of the system. The silos remained fully elastic, consistent with observation found in the literature [6-8]. The braces suffered extensive yielding without however triggering any brittle behavior. The consequences of the damage were mainly economic (collapse of part of the plant, interruption of activities, loss of content) and environmental (dispersion of polluting material). As a reference performance objective for the retrofit solution, prescription of the Eurocodes were adopted [10]. It is worth noting that different performances were evaluated using 
nonlinear static and response spectrum dynamic analyses, as it is reported in Figure 3. Although the pushover curve shows a qualitative representation of the behavior under horizontal forces, it fails to correctly estimate the actual performance of the structure since it does not take into account the vertical component. Vertical actions in combination with relative high displacements due to a torsional behavior, produce a collapse mechanism governed by buckling in the column, which can correctly be detected only using nonlinear dynamic analysis.
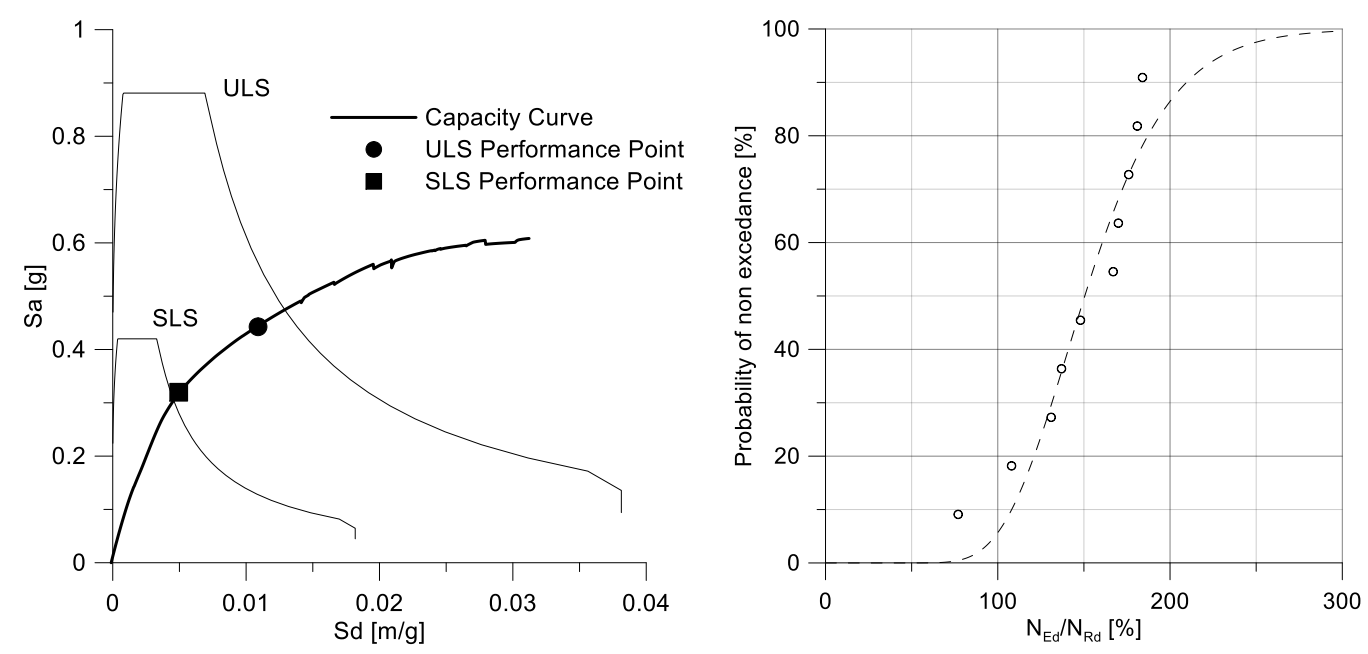

Figure 3: Structure assessment using nonlinear static analysis (left) and response spectrum dynamic analysis (right).

\section{NONLINEAR ANALYSES AND RETROFIT}

The retrofit solution chosen consists of isolation of the main mass (i.e. the silos) of the system. Curved surface sliders have been introduced between the vertical elements (pillars and columns) and the deck, thus limiting the horizontal action transmitted to the substructure and decoupling the behavior of the system. The steel columns have been connected to the pillars introducing three beams positioned below the isolation plane. The substructure in this configuration was, however, too flexible, thus reducing the effectiveness of the isolation solution (Figure 4). A vertical bracing has been introduced between the two steel columns in order to stiffen the substructure, which has been considered to remain elastic and thus has been modeled with linear elastic truss elements. The friction devices have been modeled with nonlinear link elements with parameters reported in Table 1.
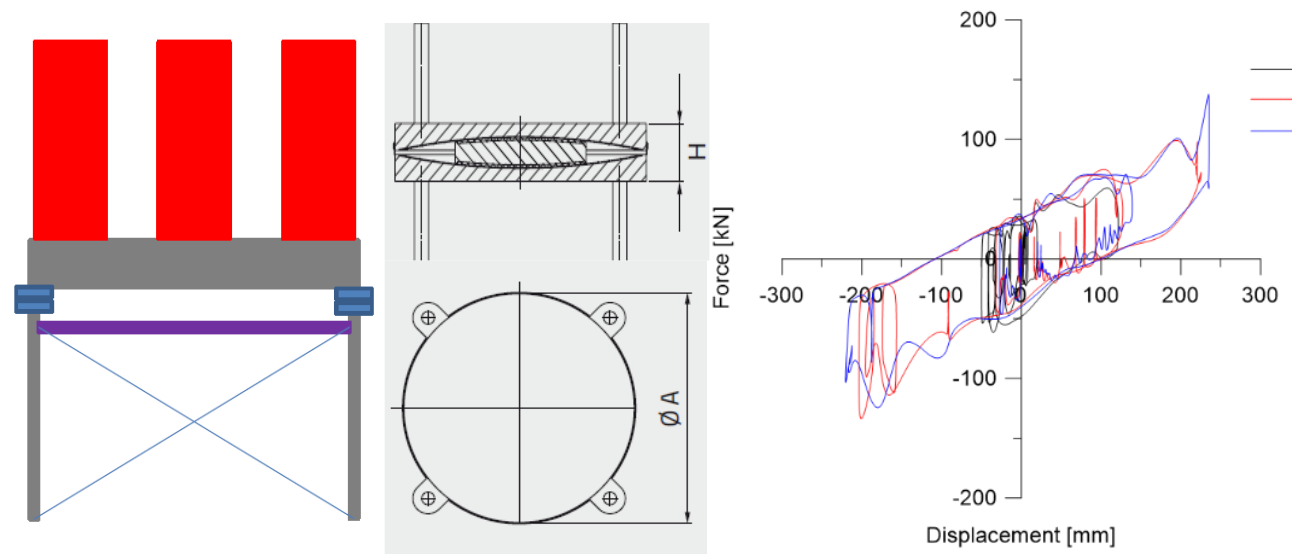

Figure 4: Retrofit scheme: Isolation and bracing of the substructure. 


\begin{tabular}{cc}
\hline Parameter & Value \\
\hline$\mu$ & $3,6 \%$ \\
$\mathrm{R}$ & $3000 \mathrm{~mm}$ \\
$\mathrm{~d}_{\max }$ & $350 \mathrm{~mm}$ \\
$\mathrm{~N}_{\mathrm{Ed}}$ & $1000 \mathrm{kN}$ \\
$\mathrm{A}$ & $580 \mathrm{~mm}$ \\
$\mathrm{H}$ & $135 \mathrm{~mm}$ \\
\hline
\end{tabular}

Table 1: Friction Isolator Device parameters.

The seismic action has been modeled with a set of unscaled Ground Motions (Figure 5) [9] and various scale factors calculated dividing the probabilistic hazard curve in regular steps. The hazard curve has been calculated from the hazard definition of the Italian Code NTC08 [11-12]. The resulting limit states however were different from Eurocodes prescriptions, for this reason other two scale factors were introduced: 0.86, corresponding to an Ultimate Limit State with an importance factor of 1.2, and 0.41, corresponding to a Serviceability Limit State with an importance factor of 1.2 (Figure 5) [10].
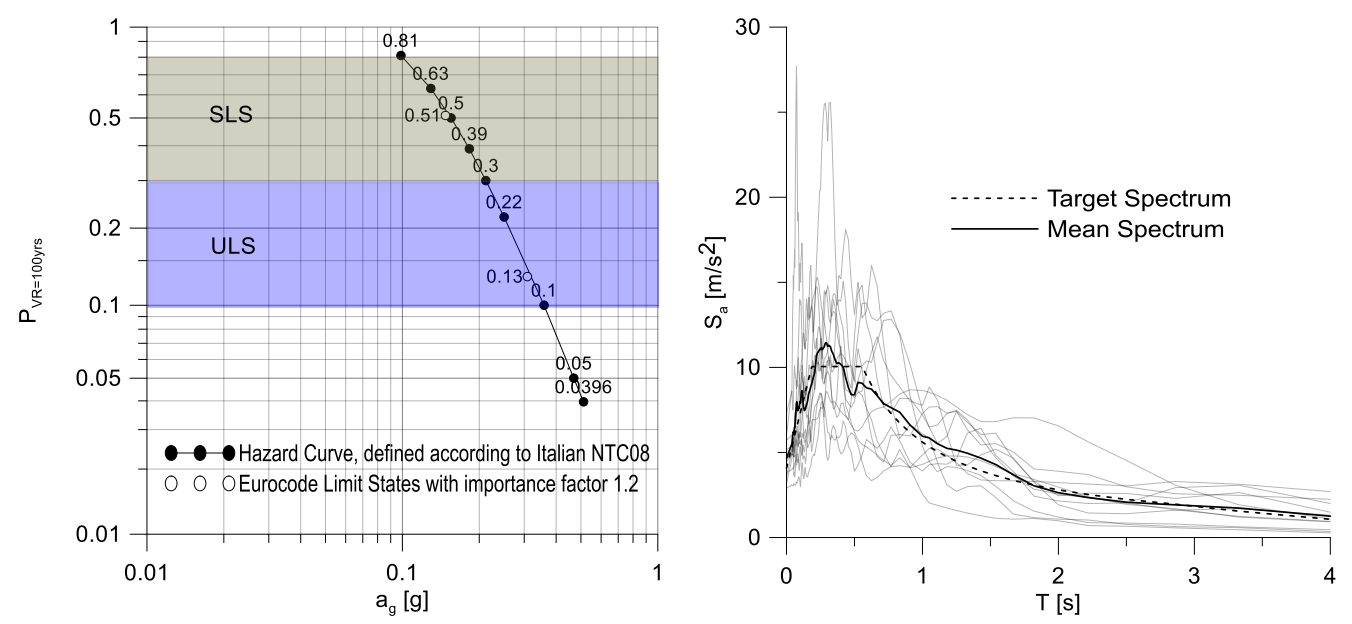

Figure 5: Action definition. Left: Probabilistic Hazard Curve. Right: Ground Motions spectra matching to the target spectrum.

The linear analyses were done using the response spectra of the set of selected ground motions. CQC was used as modal combination and CQC3 as directional combination.

Since the only source of nonlinearities, in the retrofitted structure, were the links used to model the isolation devices it has been possible to perform Fast Nonlinear which were more computationally efficient than Direct Integration method (D.I.) both in terms of time and accuracy of results, due to the issue of damping leakage [13]. Results of the modal analysis show how the introduction of the isolation devices just below the deck is effective in decoupling the structure response. Figure 6 clearly shows the differences in the modal response of the structure before and after the retrofit intervention and how the retrofit solution strongly reduces the torsional behavior of the structure. The increment in period can be found in Table 2 


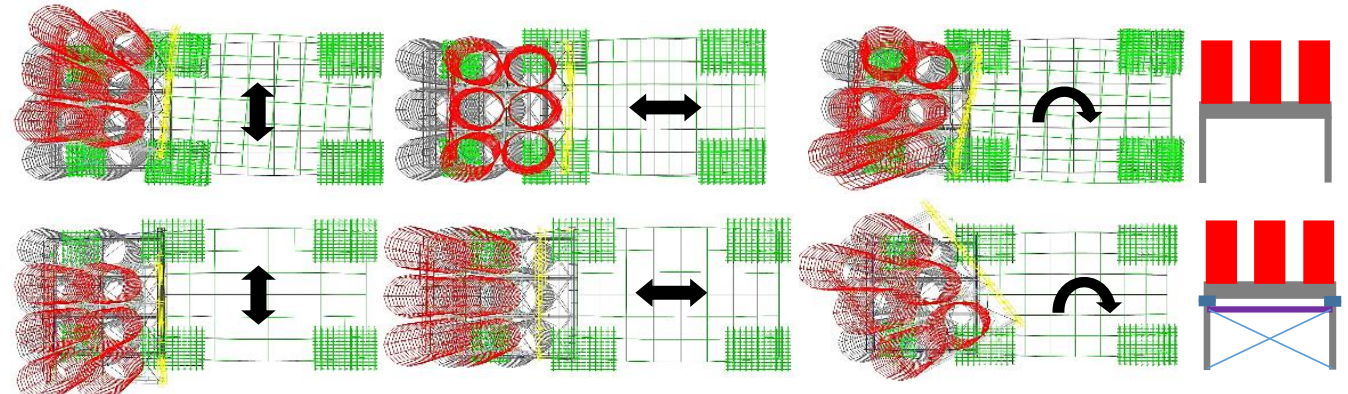

Figure 6: Comparison of the behavior of the structure at ULS.

\begin{tabular}{cccc}
\hline \multicolumn{2}{c}{ Existing } & \multicolumn{2}{c}{ Isolated } \\
\hline Period [s] & Mass & Period [s] & Mass \\
\hline 0.87 & $74 \%$ & 3.02 & $60 \%$ \\
0.65 & $81 \%$ & 3.07 & $60 \%$ \\
0.37 & $35 \%$ & 1.61 & $12 \%$ \\
\hline
\end{tabular}

Table 2: Modal Periods and Masses.

Results of the non-linear dynamic analyses presented in Figure 7 show the improvement of the structural behavior after the introduction of the isolation devices. In particular in the pre-retrofit situation, the structure exhibited a critical behavior, due to the collapse of the columns for buckling phenomena, triggering a complete collapse of the structure. The introduction of the isolation devices proves to be an effective strategy since, due to the reduction of the displacement of the substructure, the vulnerability of the steel columns is greatly reduced, both in terms of critical load and moment at the base, especially in the y direction.
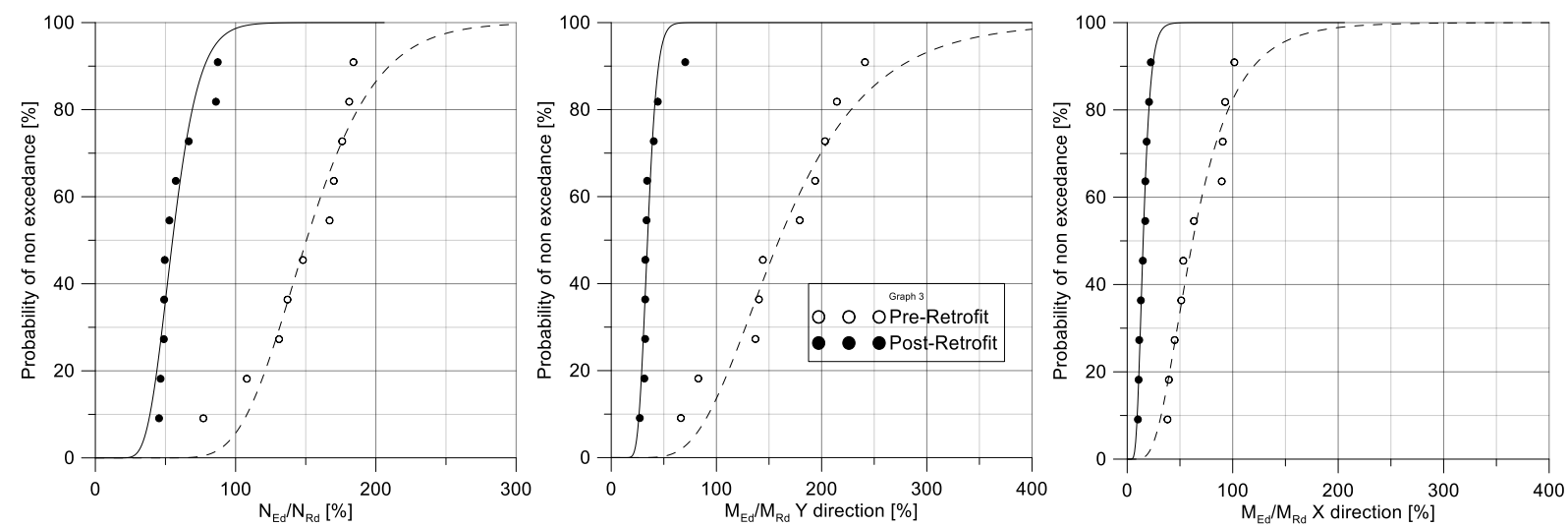

Figure 7: Comparison of the behavior of the structure at ULS.

\section{CONCLUSIONS}

Performance based assessment of an existing steel silo structure was carried out through linear, nonlinear static and incremental dynamic analyses, both in the existing and retrofit solution using sliding devices. Results have shown that:

- The complex geometry of most industrial structures needs a thorough study of the single components. Using traditional models may lead to important errors in describing correctly the behavior of the system;

- Static nonlinear analyses neglect the effect of the vertical component and may thus lead to inaccurate results; 
- The use of isolation devices regularizes the structure behavior, eliminating the torsional effects;

- The use of Direct Integration nonlinear dynamic analyses on very deformable or isolated structures, due to damping leakage phenomena, can cause a strong reduction of the displacement, thus providing nonrealistic results as compared to Fast Nonlinear Analyses;

- Placing the isolation plane just below the stock units, and thus just below the main mass, can significantly increase the performance of the sub structure, both in terms of reduction of the horizontal component and in the protection against buckling phenomena induced by the vertical component;

- The strong reduction of the stiffness of the superstructure enables the designer to have a wider range of choices in terms of stiffening the substructure, being thus able to find an optimum solution, which can take into consideration the processing activities.

\section{ACKNOWLEDGMENTS}

The research leading to these results has received funding from the European Union's Research Fund for Coal and Steel (RFCS) research programme under grant agreement $n^{\circ}$ [RFSR-CT-2013-00019].

\section{REFERENCES}

[1] S. Eshghi and M. S. Razzaghi, Performance of Industrial Facilities in the 2003 Bam, Iran, Earthquake, Earthquake Spectra, S1, 395-410, 2005.

[2] S. Fujita, I. Nakamura, O. Furuya, T. Watanabe, et al., Seismic damage of mechanical structures by the 2011 Great East Japan Earthquake, in 15th World Conference on Earthquake Engineering, Lisbon, Portugal, September 24-28, 2012.

[3] E. F. Cruz and D. Valdivia, Performance of industrial facilities in the Chilean earthquake of 27 February 2010, The Structural Design of Tall and Special Buildings, 20, 83-101, 2010.

[4] F. Braga, R. Gigliotti, G. Monti, F. Morelli, et al., Speedup of post earthquake community recovery: the case of precast industrial buildings after the Emilia 2012 earthquake, Bulletin of Earthquake Engineering, 5, 2405-2418, 2014.

[5] E. Uckan, B. Akbas, J. Shen, R. Wen, et al., Seismic performance of elevated steel silos during Van earthquake, October 23, 2011, Natural Hazards, 75, 265-287, 2015.

[6] H. Moghaddam and S. Sangi, Elephant's Foot Buckling of Cylindrical Steel Storage Tanks Subjected to Earthquake Excitation, in 6th National Congress on Civil Engineering, Semnan University, Semnan, Iran, April 26-27, 2011.

[7] R. J. Nielsen and A. S. Kiremidjian, Tall Column Reliability under Nonstationary Loads: Model Formulation, Journal of Engineering Mechanics, 7, 1107-1128, 1988.

[8] F. Paolacci, H. N. Phan, D. Corritore, S. Alessandri, et al., Seismic fragility analysis of steel storage tanks, in COMPDYN 2015 - 5th ECCOMAS Thematic Conference on Computational Methods in Structural Dynamics and Earthquake Engineering, Crete Island, Greece, May 25-27, 2015.

[9] M. Faggella, R. Laguardia, R. Gigliotti, and F. Braga, et al., Performance-based Nonlinear Response History Analysis Framework for the PROINDUSTRY Project WP2 Case Studies, in ECCOMAS Congress 2016 VII European Congress on Computational 
Methods in Applied Sciences and Engineering, Crete Island, Greece, June 5-10, 2016, (Submitted).

[10] European Committee for Standardisation, Eurocode 8 Design of structures for earthquake resistance Part 4: Silos, tanks and pipelines. 2000.

[11] Ministero delle Infrastrutture, Istruzioni per l'applicazione delle Norme Tecniche delle costruzioni, 2009.

[12] Ministero delle Infrastrutture, DM 14 gennaio 2008, Norme Tecniche per le Costruzioni, 2008.

[13] A. A. S. Sarlis and M. C. Constantinou, Modeling Triple Friction Pendulum Isolators in Program Sap2000. 1-55, 2010. 